
\title{
R Research S Suare \\ Pollution Characteristics And Health Risk Assessment of Phthalate Esters In Household Dust In Chengdu, China
}

\section{Han-Han Li}

Sichuan Agricultural University

Liu-Jun Chen

Sichuan Agricultural University

Zhan-Biao Yang

Sichuan Agricultural University

Xiao-Xun Xu

Sichuan Agricultural University

Jun-Ren Xian

Sichuan Agricultural University

Liu-Lan Zhao

Sichuan Agricultural University

\section{Song Yang}

Sichuan Agricultural University

zhang cheng ( $\sim$ cz@sicau.edu.cn )

Sichuan Agricultural University https://orcid.org/0000-0001-6211-3017

\section{Research Article}

Keywords: Phthalate esters, Chengdu, household dust, living habits, health risk assessment

Posted Date: January 27th, 2022

DOI: https://doi.org/10.21203/rs.3.rs-1186935/v1

License: (c) (i) This work is licensed under a Creative Commons Attribution 4.0 International License. Read Full License 


\section{Abstract}

The characteristics and health risks of 15 phthalate esters in household dust and the association with household attributes were investigated in Chengdu, China. The concentrations of total phthalate esters ranged from 87.9 to $3623 \mu \mathrm{g} / \mathrm{g}$. Di (2-ethylhexyl) phthalate (DEHP) was the dominant compound of phthalate esters with a median of $151 \mu \mathrm{g} / \mathrm{g}$. The statistical analysis result showed household products and synthetic polymer emission were the main sources of phthalate esters. Smoking, cooking, keeping pets and the use of wooden floor and plastic wallpaper might increase the concentrations of phthalate esters in household dust, but opening windows frequently, and increasing the sweeping frequency might cause the decrease of phthalate esters in the indoor environment. The hazard indexes $(\mathrm{HI})$ values of phthalate esters were all below 1 , showed no non-carcinogenic for inhabitants. However, the carcinogenic risk of DEHP was $2.54 \times 10^{-6}$, implying the carcinogenic risks via exposure to DEHP from Chengdu household dust were noticeable.

\section{Introduction}

Phthalate esters are extensively used in various plastic products and consumer products (Gómez-Hens \&Aguilar-Caballos 2003, Zhu et al. 2019). In China, exceed 2.1 million tons of plasticizers are produced and phthalate esters contributed to $>70 \%$ of the annual production in 2014 (Zhu et al. 2019). With the widespread production and applications, phthalate esters are almost everywhere in the environment (Chen et al. 2012). Because phthalate esters do not bind to polymers with chemical bonds, they are easily released into the environment during manufacturing, storage, and usage (Guo \&Kannan 2013, Koniecki et al. 2011, Net et al. 2015). The occurrence of phthalate esters in various environmental matrices has been investigated such as urban soil and street dust (0.0002-4.82 $\mu \mathrm{g} / \mathrm{g}$ ) (Skrbic et al. 2016), surface water (nd$16.10 \mu \mathrm{g} / \mathrm{L}$ ) (Luo et al. 2021), sediments (1.69-36.6 $\mu \mathrm{g} / \mathrm{g}$ ) (Cheng et al. 2019), as well as tobacco cultivation soils $(0.22-1.17 \mu \mathrm{g} / \mathrm{g}$ ) (Song et al. 2020), food packages (Di-2-ethylhexyl phthalate (DEHP) 0.3$103.33 \mu \mathrm{g} / \mathrm{dm}$ ) (Jarošová \&Bogdanovičová 2015), and cosmetics and personal care products (nd-25542 $\mu \mathrm{g} / \mathrm{g}$ ) (Koniecki et al. 2011). In addition, many studies have observed DEHP, di-n-butyl phthalate (DBP) and butyl benzyl phthalate (BBP) and their metabolites may abnormal internal secretions and procreation when long-term exposure, even low concentrations (Hauser \&Calafat 2005, Lovekamp-Swan \&Davis 2002).

In general, humans spend nearly $90 \%$ of their time in indoor environments including home, office, and classroom (Basaran et al. 2020, Xia et al. 2018, Zhu et al. 2019). However, people spend the whole time at home during the special time that staying at home as an effective measure against Novel Coronavirus disease 2019 (COVID-19) by many countries around the world (Chen et al. 2020, WHO 2020). Although we can eventually overcome this virus, it is also necessary to pay more attention to the quality of our home environment. Household dust is a good indicator representing the pollution level of homes (Basaran et al. 2020, Besis \&Samara 2012). The occurrence of phthalate esters in household dust from the United States, Italy and Sweden and the megacities in China (e.g., Beijing, Guangzhou, and Shanghai) have been reported (Gevao et al. 2013, Guo \&Kannan 2011, Kang et al. 2012, Orecchio et al. 2013). The previous 
studies observed there were strong associations between phthalate esters concentration in settled dust and household consumer products such as DEHP-leather polish, di-iso-butyl phthalate (DIBP), BBP, DINPflooring materials, and BBP-modern window frame (Zhang et al. 2020). Besides, resident personal habits (e.g., smoking sweeping, cooking), indoor environment and activities (e.g., decoration, the number of residents and pets), characteristics of the building (e.g., age, storey, and height) are also factors that affect the phthalate esters in indoor dust (Wang et al. 2013).

Chengdu is one of the new first-tier cities and the most livable cities in China and a key hub under the Belt and Road initiative (Li et al. 2017, Xu et al. 2018). According to the "2018 World Urbanization Prospects", there will be 10.7 million population in Chengdu in 2030 (UNDESA 2018). The total area of residential land reached 5282 ha in Chengdu in 2017, including commercial housing (53.28\%), housing of limited property rights $(23.17 \%)$, resettlement housing $(21.78 \%)$, and affordable housing $(1.77 \%)$ (Yang et al. 2017). Since 2005, the resettlement housing and affordable housing was increasing, mainly in eastern part of Chengdu (Yang et al. 2017). Affordable housing is the low-cost / leasing of commercial housing mainly provided for low-income urban populations and migrant workers (Man 2011, Shi et al. 2016). Previous studies have shown that low-income population smokes and use chemicals relatively frequently, which may cause poor indoor environmental quality and human health threat (Kolokotsa \&Santamouris 2015, Lam et al. 2017). A few studies reported the human health risks of phthalate esters in indoor dust in the USA (Guo \&Kannan 2011), Saudi Arabia (KSA) and Kuwait (Albar et al. 2017), and China (Li et al. 2021, Zhu et al. 2019). However, to our best knowledge, no studies are reporting the human health risks of phthalate esters in Chengdu household dust and the relationship between phthalate esters and Chengdu household attributes. The objectives of the present study were: (1) to investigate phthalate esters concentrations and congener profiles in household dust collected from Chengdu; (2) to assess the relationships among phthalate esters in the household dust and building characteristics and resident habits; and (3) to estimate the potential health risks of phthalate esters.

\section{Materials And Methods 2.1 Sample collection}

Household dust samples were collected by a pre-cleaned small vacuum cleaner from the floor in the living room and bedrooms in 23 households in the downtown of Chengdu (Fig. S1). All samples were sieved to remove large debris, and homogenized with the $154 \mu \mathrm{m}$ sieve and stored at desiccator until further analysis. A questionnaire was designed to gather more information from the inhabitant to evaluate their living habits, the details of the questionnaire are found in Supporting Information.

\subsection{Chemical analysis}

Freeze-dried household dust samples ( 3g) were spiked with $250 \mathrm{ng}$ of internal standards (DMP-d4, DBP$\mathrm{d} 4$ and DEHP-d4) and equilibrated at room temperature for $3 \mathrm{~h}$. Then, dust samples were extracted with $110 \mathrm{~mL}$ acetone/dichloromethane/n-hexane (1:1:1, v/v/v) in a Soxhlet extractor (USEPA 1996a), and the extracts were purified according to florisil cleanup method (USEPA 1996b). Fifteen phthalate esters were 
measured from the sample extracts by a GC 6890/MS 5973 with 30 m HP-5MS column (0.25mm diameter and $0.25 \mathrm{~mm}$ film thickness). Details about the phthalate esters analyses, QA/QC and calculation are described in the Supplementary material.

\subsection{Data analysis}

Statistical tests were conducted with SPSS 23.0 for Windows. Kolmogorov-Smirnov test was utilized to examine the normal probability function of the concentration data. Principal component analysis (PCA) and Spearman's correlation coefficient analysis were carried out to identify the possible sources and the relationships between dust-phthalate esters and household factors.

\section{Results And Discussion}

\subsection{Phthalate esters in household dust}

The concentrations of phthalate esters in household dust collected from Chengdu are shown in Table S1. Fifteen phthalate esters were detected in household dust samples with a detection frequency from 52.2 to $100 \%$. The concentrations of total phthalate esters varied from 87.9 to $3623 \mu \mathrm{g} / \mathrm{g}$ with a median of 290 $\mu \mathrm{g} / \mathrm{g}$ and a mean of $733 \mu \mathrm{g} / \mathrm{g}$ (Table S1). Comparison with other first-tier cities in Eastern China (e.g., Beijing, median $255 \mu \mathrm{g} / \mathrm{g}$ and Shanghai, median $401 \mu \mathrm{g} / \mathrm{g}$ and Guangzhou, median $173 \mu \mathrm{g} / \mathrm{g}$ ) (Guo \&Kannan 2011) (Fig. 1), there may not be a significant difference of phthalate esters levels in household dust samples between Chengdu and these cities. While lower phthalate esters concentration were observed in Chengdu compared to that found in other first-tier cities in Western China (e.g., Chongqing, median $1751 \mu \mathrm{g} / \mathrm{g}$ and Xi'an, median $1149 \mu \mathrm{g} / \mathrm{g}$ ) (Bu et al. 2016, Wang et al. 2014), and that found in other city around the world, such as the USA (median $396 \mu \mathrm{g} / \mathrm{g}$ ) (Guo \&Kannan 2011), Kuwait (median $2384 \mu \mathrm{g} / \mathrm{g}$ ) (Gevao et al. 2013), Italy (mean $1289 \mu \mathrm{g} / \mathrm{g}$ ) and Sweden (mean $1055 \mu \mathrm{g} / \mathrm{g})$ (Orecchio et al. 2013). However, it is worth noting that the extremely high phthalate esters concentrations (exceed 3000 $\mu \mathrm{g} / \mathrm{g}$ ) also were found in some sampling sites in Chengdu. Thus, for a better understanding of phthalate esters occurrence in Chengdu household dust, more detailed composition profiles and potential sources of phthalate esters are required.

\subsection{Composition profiles of phthalate esters}

Consistent with that was reported in other studies (Abdi et al. 2021, Guo \&Kannan 2011, Zhang et al. 2013), the dominant compound of phthalate esters in all dust samples collected from Chengdu was DEHP, which ranged from 48.2 to $2621 \mu \mathrm{g} / \mathrm{g}$, with a median of $151 \mu \mathrm{g} / \mathrm{g}$ and a mean of $452 \mu \mathrm{g} / \mathrm{g}$ (Table S1). The concentrations of DEHP were 2-14 times higher than the concentrations of DCHP (median 89.2 $\mu \mathrm{g} / \mathrm{g}$ ), DBP (median $31.2 \mu \mathrm{g} / \mathrm{g}$ ) and DIBP (median $11.5 \mu \mathrm{g} / \mathrm{g}$ ), and 100-1000 times higher than other phthalate esters (Fig. 2 and Table S1). DEHP is widely used in plastic products and decoration materials (e.g., floor and wall covering, toys, and adhesives) and can be released into the indoor environment through evaporation, aging, and abrasion (Bornehag et al. 2005, Zhang et al. 2020). While DBP and DIBP also showed relatively higher levels in the household dust, which might be associated with that DBP and 
DIBP as the main additives used in personal care products (e.g., cosmetics and pharmaceutical coatings) (Li et al. 2021, Net et al. 2015). In addition, the low levels of other phthalate esters such as DEP and DMP were observed in this study, which is consistent with the reported results from indoor dust samples in other cities (Guo \&Kannan 2011, Orecchio et al. 2013), that could be due to the high volatility and high vapor pressure causing the low molecular weight phthalate esters mainly in gas phase than that in dust phase (Basaran et al. 2020, Bergh et al. 2011). Noteworthy, although it's consistent with the profile in many cities all over the world that DEHP showed the largest proportion in Chengdu household dust (Fig. 1), DEHP concentrations in this study were 10 to 15 times lower than the results reported in previous studies, such as Chongqing, China (median $1543 \mu \mathrm{g} / \mathrm{g}$ ) (Bu et al. 2016), and Kuwait (median $2256 \mu \mathrm{g} / \mathrm{g}$ ) (Bergh et al. 2011) (Fig. 1). The relatively lower concentrations of DEHP in this study might reflect the trend of decreasing DEHP due to worldwide regulations or restrictions on the use of DEHP (Salthammer et al. 2018, Zhang et al. 2020). In particular, DCHP contributed $30.7 \%$ to the total phthalate esters in this study, the result was different from previous reports from China (Beijing, Guangzhou, Shanghai), the USA, and Kuwait (0 to $1.8 \%$ ) of the total phthalate esters in household dust (Gevao et al. 2013, Guo \&Kannan 2011). DCHP is a common plasticizer ingredient for ethyl cellulose, nitrocellulose, vinyl acetate, polyvinyl chloride, and resins, usually be added to the polymers to make these polymers more flexible (Lv et al. 2019, Schecter et al. 2013). As well as DCHP has been detected in many foods and packaging materials (Fierens et al. 2012, Schecter et al. 2013). The reasons underlying the high DCHP Chengdu household dust are unknown at present, but it should be drawn a lot of attention due to growing evidence demonstrated that DCHP had similar potency to DEHP or DBP in the induction of adverse effects on mammalian development and reproductive system (Aydogan Ahbab \&Barlas 2013, Li et al. 2016, Lv et al. 2019).

\subsection{Possible sources of phthalate esters}

Principal component analysis (PCA) has been widely used to elucidate the relationship among contaminants and identify their probable sources in various environmental mediums (Cheng et al. 2019, Gu et al. 2018). Kaiser-Meyer-Olkin (KMO) and Bartlett's sphericity test results were 0.75 and 297.91, respectively ( $\mathrm{df}=105, p<0.01)$, indicating PCA may be a helpful tool in the identification of distinct phthalate esters sources. As shown in Fig. 3, the first-two principal components (PC1 and PC2) were extracted and collectively explained more than $81.0 \%$ of the total variance of the phthalate esters in all household dust samples. PC1 (57.4\%) was heavily loaded by DBP, DEP, DINP, DAP, DMP, DIBP, DPP and BBP. The lower molecular weight phthalate esters, such as DMP, DEP, DBP and BBP are typically used in cosmetics and personal care products, BBP also widely used in construction materials and home furnishings such as vinyl flooring, adhesives, and synthetic leather (Gómez-Hens \&Aguilar-Caballos 2003, $\mathrm{Ma}$ et al. 2020, Net et al. 2015). PC2 contributed to $23.6 \%$ of the total variance with strong positive loadings of DNOP, DCHP, DEHP, DNP and DEEP. These high-molecular weights phthalate esters were widely used as plasticizers to impart flexibility and general handling properties to PVC and synthetic polymer (Net et al. 2015, Schecter et al. 2013, Zhang et al. 2020). The multiple linear regression (MLR) analysis is performed on the factor scores of PCA, and then quantitative evaluation of the relative 
contribution of each identified source of pollutants (Cheng et al. 2019, Ke et al. 2017). In the present study, the regression equations are expressed as follow:

Standardized phthalate esters $=0.868 \mathrm{PC} 1+0.373 \mathrm{PC} 2\left(\mathrm{R}^{2}=0.870, p<0.001\right)$

The relative contributions of $\mathrm{PC} 1$ and $\mathrm{PC} 2$ to the total phthalate esters burden in household dust from Chengdu were calculated from the coefficients, showing PC 1 (personal care products and household chemicals emission) to contribute $69.9 \%$, whereas PC 2 (PVC and other synthetic polymer emissions) contributed $30.0 \%$ of phthalate esters in household dust from Chengdu.

In addition, a recent study demonstrated that strong associations between phthalate esters in Chinese household dust and household consumer products such as flooring materials and modern window frame (Zhang et al. 2020). Thus, based on the data from the questionnaire, a total of 13 household factors were defined and calculated the possible relationship with phthalate esters concentrations in Chengdu household dust (Table S2 and Fig. 4). According to the statistical results can identify three categories (e.g., living habits, decorations, and others) of the household factors were found strong associations with dust-phthalate esters (Fig. 4). The living habits included smoking, sweeping frequency, window opening habits, and cooking frequency in this study. Strong positive correlations were observed between smoking and DMP, DEP, and DIBP $(p<0.001)$, and DBP, DEHP, DINP, and total phthalate esters $(p<0.01)$, DEEP, DCHP, and DNOP $(p<0.05)$ (Fig. 4). These results indicated smoking may be one of the most important sources of phthalate esters in household dust in Chengdu. Wang et al. (2020) observed pregnant women exposure the environmental tobacco smoke (ETS) may increase the concentrations of phthalate esters (DIBP, DBP, DPP, and DINP) in their urinary. Song et al. (2020) found the long-term application of plastic film and agricultural inputs (irrigation water and fertilizers) might increase phthalate esters concentrations in tobacco cultivation soils, and then cause the accumulation of phthalate esters in tobacco leaves. In addition, phthalate esters may be released into the household environment from cigarette packaging and printing ink (Gong et al. 2018). Meanwhile, sweeping frequency showed a strong correlation with DMP, DEP, and total phthalate esters $(p<0.01)$, with DIBP, DBP, DCHP, DINP, and DNP ( $p<$ 0.05 ) (Fig. 4), indicating the higher sweeping frequency to be effective in reducing the accumulation of phthalate esters in household dust. Furthermore, window opening habits also have a strong influence on phthalates esters concentration in the household dust. Pei et al. (2018) found the emission rate of phthalate esters could be increased from the source materials with indoor temperature increasing and the ventilation could reduce the phthalate esters concentration in the dust-phase, so increasing the time to open windows for ventilation and the frequency of house cleaning, which is beneficial to maintaining a good indoor environment. Noteworthy, there were positive correlations among cooking frequency and DEHP, DCHP $(p<0.01)$, DNOP, and total phthalate esters $(p<0.05)$, indicated that cooking also was a contributor to phthalate esters in household dust, which could be explained by synthetic condiments and food packaging would be used during the cooking (Fierens et al. 2012, Jarošová \&Bogdanovičová 2015, Schecter et al. 2013). 
Consistent with previous studies (Ait Bamai et al. 2014, Li et al. 2021, Zhang et al. 2020), strong associations were found between home decorations (e.g., floor cover and wall cover) and phthalate esters in the household dust $(p<0.05)$. The range of associations were observed between floor cover and DCHP, and DEHP ( $p<0.01)$, and DEEP, DNOP, and total phthalate esters $(p<0.05)$ (Fig. 4), implying the wooden floors might be found higher concentrations of phthalate esters in the household dust, corroborating wooden floors especially laminated wood floors suspected as the source of phthalate esters (Zhang et al. 2013, Zhang et al. 2020). Plenty of phthalate esters were added as adhesives in the manufacturing process of laminated woods to improve the adhesion property (Ait Bamai et al. 2014, Zhang et al. 2020). In addition, wall covers were associated with DIBP, DEHP, DNOP, DINP, and total phthalate esters $(p<$ 0.001), with DMP, DBP, DCHP, and DNP ( $p$ 0.01) (Fig. 4), the results might provide further evidence that plastic wallpaper and latex paints were the important sources for phthalate esters in the household dust (Shinohara et al. 2019).

The results also showed that positive correlations between pets and phthalate esters in this study (Fig. 4). The high-molecular weights phthalates esters (e.g., DEHP and DINP) are restricted in children's toys and child-care articles in the US, Europe and China, but there are no restrictions on pet toys (Wooten \&Smith 2013). Many previous studies had reported the detection of high-molecular weights phthalate esters in pet toys, such as, concentrations of DEHP (4 out of 13) and DINP (10 out of 13) in 13 pet toys ranged from 6.9 to $54 \%(\mathrm{v} / \mathrm{v})$ in Denmark, and 5 out of 6 phthalates were detected in canine toys and training devices in the US (Müller et al. 2006, Wooten \&Smith 2013). Notably, the correlations between DCHP and household factors were similar to that of DEHP, indicating DCHP not only had similar potency to DEHP in the induction of adverse effects on the reproductive system, but also might have similar sources in the indoor environment (Aydogan Ahbab \&Barlas 2013, Lv et al. 2019).

In this study, although non-significant correlations were found between building characteristics (e.g., floor level, age of building, and area of building) and phthalate esters in the household dust, previous studies found that phthalate esters might accumulate especially high-molecular weights phthalate esters in household dust in the older house since the erosion and abrasion of building materials with time (Bornehag et al. 2005, Shinohara et al. 2019). In addition, the high-rise and large dwelling-size houses have a stronger inhibitory effect on the accumulation of phthalate esters in household dust. The high-rise building causing the pollutants (e.g., heavy metals, polycyclic aromatic hydrocarbons, and phthalate esters) loaded in the particulates would be difficultly resuspended in vertical directions, and large size house enhancing horizontal diffusion space of pollutants, resulting in the decrease of pollutants concentrations in the indoor environment (Bornehag et al. 2005, Hang et al. 2012).

\subsection{Human health risks of phthalate esters}

To estimate the risks of phthalate esters exposure in household dust from Chengdu, the average daily dose (ADD, $\mu \mathrm{g} / \mathrm{kg}$-bw/day) of DMP, DEP, DIBP, DBP, BBP, DEHP and DNOP via ingestion, inhalation, and dermal absorption pathway were estimated for children and adults (Table 1). The total ADD of phthalate esters from household dust for children was about 7.5 times higher than adults, implying children were more susceptible to phthalate esters intake than adults. Similar results were observed in previous studies 
(Albar et al. 2017, Li et al. 2021, Zhu et al. 2019). The ADDs of phthalate esters for children and adults via dust ingestion were 2-7 orders of magnitude higher than dermal adsorption and dust inhalation, indicating the household dust ingestion was the principal pathway for inhabitant exposure to phthalate esters. The results were consistent with previous reports (Li et al. 2021, Zhu et al. 2019). 
Table 1

Risk assessment of human exposure to phthalate esters via household dust.

\begin{tabular}{|c|c|c|c|c|c|c|c|c|}
\hline & & DMP & DEP & DIBP & DBP & BBP & DEHP & DNOP \\
\hline \multirow[t]{2}{*}{ ADDing } & Children & $\begin{array}{l}4.68 \mathrm{E}- \\
04\end{array}$ & $\begin{array}{l}1.03 \mathrm{E}- \\
03\end{array}$ & $\begin{array}{l}5.69 \mathrm{E}- \\
02\end{array}$ & $\begin{array}{l}3.42 \mathrm{E}- \\
01\end{array}$ & $\begin{array}{l}9.39 \mathrm{E}- \\
03\end{array}$ & $1.83 \mathrm{E}+00$ & $\begin{array}{l}4.30 \mathrm{E}- \\
03\end{array}$ \\
\hline & Adults & $\begin{array}{l}6.24 \mathrm{E}- \\
05\end{array}$ & $\begin{array}{l}1.37 \mathrm{E}- \\
04\end{array}$ & $\begin{array}{l}7.58 \mathrm{E}- \\
03\end{array}$ & $\begin{array}{l}4.56 \mathrm{E}- \\
02\end{array}$ & $\begin{array}{l}1.25 \mathrm{E}- \\
03\end{array}$ & 2.44E-01 & $\begin{array}{l}5.73 \mathrm{E}- \\
04\end{array}$ \\
\hline \multirow[t]{2}{*}{ ADDinh } & Children & $\begin{array}{l}4.36 \mathrm{E}- \\
11\end{array}$ & $\begin{array}{l}9.58 \mathrm{E}- \\
11\end{array}$ & $\begin{array}{l}5.30 \mathrm{E}- \\
09\end{array}$ & $\begin{array}{l}3.18 \mathrm{E}- \\
08\end{array}$ & $\begin{array}{l}8.74 \mathrm{E}- \\
10\end{array}$ & $1.71 \mathrm{E}-07$ & $\begin{array}{l}4.01 \mathrm{E}- \\
10\end{array}$ \\
\hline & Adults & $\begin{array}{l}3.06 \mathrm{E}- \\
11\end{array}$ & $\begin{array}{l}6.72 \mathrm{E}- \\
11\end{array}$ & $\begin{array}{l}3.72 \mathrm{E}- \\
09\end{array}$ & $\begin{array}{l}2.23 \mathrm{E}- \\
08\end{array}$ & $\begin{array}{l}6.14 \mathrm{E}- \\
10\end{array}$ & $1.20 \mathrm{E}-07$ & $\begin{array}{l}2.81 \mathrm{E}- \\
10\end{array}$ \\
\hline \multirow[t]{2}{*}{ ADDder } & Children & $\begin{array}{l}4.37 \mathrm{E}- \\
06\end{array}$ & $\begin{array}{l}9.60 \mathrm{E}- \\
06\end{array}$ & $\begin{array}{l}5.31 \mathrm{E}- \\
04\end{array}$ & $\begin{array}{l}3.19 \mathrm{E}- \\
03\end{array}$ & $\begin{array}{l}8.76 \mathrm{E}- \\
05\end{array}$ & 1.71E-02 & $\begin{array}{l}4.01 \mathrm{E}- \\
05\end{array}$ \\
\hline & Adults & $\begin{array}{l}8.30 \mathrm{E}- \\
07\end{array}$ & $\begin{array}{l}1.82 \mathrm{E}- \\
06\end{array}$ & $\begin{array}{l}1.01 \mathrm{E}- \\
04\end{array}$ & $\begin{array}{l}6.06 \mathrm{E}- \\
04\end{array}$ & $\begin{array}{l}1.66 \mathrm{E}- \\
05\end{array}$ & $3.25 \mathrm{E}-03$ & $\begin{array}{l}7.63 \mathrm{E}- \\
06\end{array}$ \\
\hline \multirow[t]{2}{*}{ HQing } & Children & $\begin{array}{l}4.68 \mathrm{E}- \\
08\end{array}$ & $\begin{array}{l}1.29 \mathrm{E}- \\
06\end{array}$ & $\begin{array}{l}5.69 \mathrm{E}- \\
04\end{array}$ & $\begin{array}{l}3.42 \mathrm{E}- \\
03\end{array}$ & $\begin{array}{l}4.69 \mathrm{E}- \\
05\end{array}$ & $9.16 \mathrm{E}-02$ & $\begin{array}{l}1.08 \mathrm{E}- \\
05\end{array}$ \\
\hline & Adults & $\begin{array}{l}6.24 \mathrm{E}- \\
09\end{array}$ & $\begin{array}{l}1.71 \mathrm{E}- \\
07\end{array}$ & $\begin{array}{l}7.58 \mathrm{E}- \\
05\end{array}$ & $\begin{array}{l}4.56 \mathrm{E}- \\
04\end{array}$ & $\begin{array}{l}6.26 \mathrm{E}- \\
06\end{array}$ & $1.22 \mathrm{E}-02$ & $\begin{array}{l}1.43 \mathrm{E}- \\
06\end{array}$ \\
\hline \multirow[t]{2}{*}{ HQinh } & Children & $\begin{array}{l}4.36 \mathrm{E}- \\
15\end{array}$ & $\begin{array}{l}1.20 \mathrm{E}- \\
13\end{array}$ & $\begin{array}{l}5.30 \mathrm{E}- \\
11\end{array}$ & $\begin{array}{l}3.18 \mathrm{E}- \\
10\end{array}$ & $\begin{array}{l}4.37 \mathrm{E}- \\
12\end{array}$ & 8.53E-09 & $\begin{array}{l}1.00 \mathrm{E}- \\
12\end{array}$ \\
\hline & Adults & $\begin{array}{l}3.06 \mathrm{E}- \\
15\end{array}$ & $\begin{array}{l}8.41 \mathrm{E}- \\
14\end{array}$ & $\begin{array}{l}3.72 \mathrm{E}- \\
11\end{array}$ & $\begin{array}{l}2.23 \mathrm{E}- \\
10\end{array}$ & $\begin{array}{l}3.07 \mathrm{E}- \\
12\end{array}$ & 5.99E-09 & $\begin{array}{l}7.03 \mathrm{E}- \\
13\end{array}$ \\
\hline \multirow[t]{2}{*}{ HQder } & Children & $\begin{array}{l}4.37 \mathrm{E}- \\
10\end{array}$ & $\begin{array}{l}1.20 \mathrm{E}- \\
08\end{array}$ & $\begin{array}{l}5.31 \mathrm{E}- \\
06\end{array}$ & $\begin{array}{l}3.19 \mathrm{E}- \\
05\end{array}$ & $\begin{array}{l}4.38 \mathrm{E}- \\
07\end{array}$ & 8.55E-04 & $\begin{array}{l}1.00 \mathrm{E}- \\
07\end{array}$ \\
\hline & Adults & $\begin{array}{l}8.30 \mathrm{E}- \\
11\end{array}$ & $\begin{array}{l}2.28 \mathrm{E}- \\
09\end{array}$ & $\begin{array}{l}1.01 \mathrm{E}- \\
06\end{array}$ & $\begin{array}{l}6.06 \mathrm{E}- \\
06\end{array}$ & $\begin{array}{l}8.32 \mathrm{E}- \\
08\end{array}$ & $1.62 \mathrm{E}-04$ & $\begin{array}{l}1.91 \mathrm{E}- \\
08\end{array}$ \\
\hline \multirow[t]{2}{*}{$\mathrm{HI}$} & Children & $\begin{array}{l}4.72 \mathrm{E}- \\
08\end{array}$ & $\begin{array}{l}1.30 \mathrm{E}- \\
06\end{array}$ & $\begin{array}{l}5.74 \mathrm{E}- \\
04\end{array}$ & $\begin{array}{l}3.45 \mathrm{E}- \\
03\end{array}$ & $\begin{array}{l}4.74 \mathrm{E}- \\
05\end{array}$ & $9.25 \mathrm{E}-02$ & $\begin{array}{l}1.09 \mathrm{E}- \\
05\end{array}$ \\
\hline & Adults & $\begin{array}{l}6.32 \mathrm{E}- \\
09\end{array}$ & $\begin{array}{l}1.74 \mathrm{E}- \\
07\end{array}$ & $\begin{array}{l}7.68 \mathrm{E}- \\
05\end{array}$ & $\begin{array}{l}4.62 \mathrm{E}- \\
04\end{array}$ & $\begin{array}{l}6.34 \mathrm{E}- \\
06\end{array}$ & 1.24E-02 & $\begin{array}{l}1.45 \mathrm{E}- \\
06\end{array}$ \\
\hline LADD & & & & & & $\begin{array}{l}9.30 \mathrm{E}- \\
07\end{array}$ & $1.81 \mathrm{E}-04$ & \\
\hline
\end{tabular}

Note, ADDing, ADDinh, and ADDder indicates the average daily dose $(\mu \mathrm{g} / \mathrm{kg}$-bw $/$ day) of individual PAEs via ingestion, inhalation, and dermal absorption exposure; HQing, HQinh, and HQder suggests hazard quotient of individual PAEs by ingestion, inhalation, and dermal absorption exposure; $\mathrm{HI}$ represents hazard index; LADD denotes the lifetime average daily exposure doses of the carcinogenic PAEs; $C R$ is carcinogenic risk. Bold indicates the values above $1 \times 10^{-6}$, which might pose health risk to inhabitants. 


\begin{tabular}{|c|c|c|c|c|c|c|}
\hline DMP & DEP & DIBP & DBP & BBP & DEHP & DNOP \\
\hline $\mathrm{CR}$ & & & & $\begin{array}{l}1.77 \mathrm{E}- \\
09\end{array}$ & 2.54E-06 & \\
\hline \multicolumn{7}{|c|}{$\begin{array}{l}\text { Note, ADDing, ADDinh, and ADDder indicates the average daily dose }(\mu \mathrm{g} / \mathrm{kg} \text {-bw/day) of individual } \\
\text { PAEs via ingestion, inhalation, and dermal absorption exposure; HQing, HQinh, and HQder suggests } \\
\text { hazard quotient of individual PAEs by ingestion, inhalation, and dermal absorption exposure; HI } \\
\text { represents hazard index; LADD denotes the lifetime average daily exposure doses of the carcinogenic } \\
\text { PAEs; CR is carcinogenic risk. Bold indicates the values above } 1 \times 10^{-6}, \text { which might pose health risk } \\
\text { to inhabitants. }\end{array}$} \\
\hline
\end{tabular}

Furthermore, the values of $\mathrm{HI}$ for all phthalate esters were all below 1 suggesting that no noncarcinogenic risks of phthalate esters in household dust were found for Chengdu inhabitants (Table 1). The $\mathrm{HI}$ values of individual phthalate ester in the household dust samples in the decreasing order as follows: DEHP > DBP > DIBP > BBP > DNOP > DEP > DMP (Table 1). The carcinogenic risk for human exposure to BBP and DEHP in the household dust was $1.77 \times 10^{-9}$ and $2.54 \times 10^{-6}$, respectively (Table 1), which cancer risk of DEHP was in the range of $10^{-6}$ to $10^{-4}$, indicating that there might be a potential carcinogenic risk of DEHP in household dust in Chengdu.

\section{Conclusions}

The present study investigated the concentrations of phthalate esters in household dust from Chengdu. DEHP was the largest proportion of phthalate esters in this study, but its concentrations were 10 to 15 times lower than the results reported in previous studies. Besides, DCHP contributed $30.7 \%$ to the total phthalate esters in the present study, the result was different from previous reports from China. Living habits (smoking, sweeping frequency, window opening habits, and cooking frequency), home decorations (floor cover and wall cover) and other factors such as pets can significantly affect the concentrations of phthalate esters in household dust in Chengdu. Particularly, the inhabitants in Chengdu might face the potential carcinogenic risk of phthalate esters in household dust. Thus, some suggestion to the general population in Chengdu, (1) Smoking less and opening windows frequently to maintain the indoor air circulation; (2) The pet supplies need to be stocked in a fixed place; (3) Increasing the sweeping frequency of indoor environment, especially the older houses.

\section{Declarations}

Authors' contribution Ha-Han Li: Writing- original draft. Liu-Jun Chen:Data curation. Zhan-Biao Yang: Investigation. Jun-Ren Xian: data curation. Xiao-Xun Xu:Supervision. Liu-lan Zhao: Investigation. Song Yang: Investigation. Zhang Cheng: Writing - review \& editing.

Funding The research works of the above study were funded by the National Natural Science Foundation of China (No. 21507095), and Sichuan Provincial Youth Science and Technology Fund (No.2017JQ0035).

Data availability All data generated or analyzed during this study are included in this published article. 
Ethics approval and consent to participate The manuscript did not contain any reporting studies involving human data.

Consent for publication Themanuscript does not contain any individual person data.

Conflict of interest The authors declare no competing interests.

\section{References}

1. Abdi S, Sobhanardakani S, Lorestani B, Cheraghi M, Panahi HA (2021) : Analysis and health risk assessment of phthalate esters (PAEs) in indoor dust of preschool and elementary school centers in city of Tehran, Iran.Environ Sci Pollut Res Int,1-2

2. Ait Bamai Y, Araki A, Kawai T, Tsuboi T, Saito I, Yoshioka E, Kanazawa A, Tajima S, Shi C, Tamakoshi A, Kishi R (2014) Associations of phthalate concentrations in floor dust and multi-surface dust with the interior materials in Japanese dwellings. Sci Total Environ 468-469:147-157

3. Albar HMSA, Ali N, Shahzad K, Ismail IMI, Rashid MI, Wang W, Ali LN, Eqani SAMAS (2017) Phthalate esters in settled dust of different indoor microenvironments; source of non-dietary human exposure. Microchem J 132:227-232

4. Aydogan Ahbab M, Barlas N (2013) Developmental effects of prenatal di-n-hexyl phthalate and dicyclohexyl phthalate exposure on reproductive tract of male rats: Postnatal outcomes. Food Chem Toxicol 51:123-136

5. Basaran B, Soylu GN, Yilmaz Civan M (2020) Concentration of phthalate esters in indoor and outdoor dust in Kocaeli, Turkey: implications for human exposure and risk. Environ Sci Pollut Res Int 27:1808-1824

6. Bergh C, Torgrip R, Emenius G, Ostman C (2011) Organophosphate and phthalate esters in air and settled dust - a multi-location indoor study. Indoor Air 21:67-76

7. Besis A, Samara C (2012) Polybrominated diphenyl ethers (PBDEs) in the indoor and outdoor environments-a review on occurrence and human exposure. Environ Pollut 169:217-229

8. Bornehag CG, Lundgren B, Weschler CJ, Sigsgaard T, Hagerhed-Engman L, Sundell J (2005) Phthalates in indoor dust and their association with building characteristics. Environ Health Perspect 113:1399-1404

9. Bu Z, Zhang Y, Mmereki D, Yu W, Li B (2016) Indoor phthalate concentration in residential apartments in Chongqing, China: Implications for preschool children's exposure and risk assessment. Atmos Environ 127:34-45

10. Chen L, Zhao Y, Li LX, Chen BH, Zhang YH (2012) Exposure assessment of phthalates in nonoccupational populations in China. Sci Total Environ 427:60-69

11. Chen S, Yang J, Yang W, Wang C, Bärnighausen T (2020) COVID-19 control in China during mass population movements at New Year. The Lancet 395:764-766 
12. Cheng Z, Liu JB, Gao M, Shi GZ, Fu XJ, Cai P, Lv YF, Guo ZB, Shan CQ, Yang ZB, Xu XX, Xian JR, Yang YX, Li KB, Nie XP (2019) Occurrence and distribution of phthalate esters in freshwater aquaculture fish ponds in Pearl River Delta, China. Environ Pollut 245:883-888

13. Fierens T, Servaes K, Van Holderbeke M, Geerts L, De Henauw S, Sioen I, Vanermen G (2012) Analysis of phthalates in food products and packaging materials sold on the Belgian market. Food Chem Toxicol 50:2575-2583

14. Gevao B, Al-Ghadban AN, Bahloul M, Uddin S, Zafar J (2013) Phthalates in indoor dust in Kuwait: implications for non-dietary human exposure. Indoor Air 23:126-133

15. Gómez-Hens A, Aguilar-Caballos MP (2003) Social and economic interest in the control of phthalic acid esters. Trends Anal Chem 22:847-857

16. Gong Y, Zhou S, Xu H, Ge J, Jin L, Pan J (2018) Research of Cigarette Packaging Printing Ink Without Phthalate Plasticizer, Applied Sciences in Graphic Communication and Packaging. Springer, pp 745752

17. Gu YG, Ke CL, Liu Q (2018) Characterization, sources, and ecological hazards of polycyclic aromatic hydrocarbons in the intertidal sediments of Zhelin Bay, the biggest mariculture area on the eastern Guangdong coast of China. Mar Pollut Bull 130:192-197

18. Guo Y, Kannan K (2011) Comparative assessment of human exposure to phthalate esters from house dust in China and the United States. Environ Sci Technol 45:3788-3794

19. Guo Y, Kannan K (2013) A survey of phthalates and parabens in personal care products from the United States and its implications for human exposure. Environ Sci Technol 47:14442-14449

20. Hang J, Li Y, Sandberg M, Buccolieri R, Di Sabatino S (2012) The influence of building height variability on pollutant dispersion and pedestrian ventilation in idealized high-rise urban areas. Build Environ 56:346-360

21. Hauser R, Calafat AM (2005) Phthalates and human health. Occup Environ Med 62:806-818

22. Jarošová A, Bogdanovičová S (2015) : Phthalate migration from packaging materials into food. Potravinarstvo 9

23. Kang Y, Man YB, Cheung KC, Wong MH (2012) Risk assessment of human exposure to bioaccessible phthalate esters via indoor dust around the Pearl River Delta. Environ Sci Technol 46:8422-8430

24. Ke CL, Gu YG, Liu Q (2017) Polycyclic Aromatic Hydrocarbons (PAHs) in Exposed-Lawn Soils from 28 Urban Parks in the Megacity Guangzhou: Occurrence, Sources, and Human Health Implications. Arch Environ Contam Toxicol 72:496-504

25. Kolokotsa D, Santamouris M (2015) Review of the indoor environmental quality and energy consumption studies for low income households in Europe. Sci Total Environ 536:316-330

26. Koniecki D, Wang R, Moody RP, Zhu J (2011) Phthalates in cosmetic and personal care products: concentrations and possible dermal exposure. Environ Res 111:329-336

27. Lam CLK, Guo VY, Wong CKH, Yu EYT, Fung CSC (2017) Poverty and health-related quality of life of people living in Hong Kong: comparison of individuals from low-income families and the general 
population. J Public Health (Oxf) 39:258-265

28. Li X, Chen X, Hu G, Li L, Su H, Wang Y, Chen D, Zhu Q, Li C, Li J, Wang M, Lian Q, Ge RS (2016) : Effects of in Utero Exposure to Dicyclohexyl Phthalate on Rat Fetal Leydig Cells. Int J Environ Res Public Health13

29. Li X, Zhang W, Lv J, Liu W, Sun S, Guo C, Xu J (2021) : Distribution, source apportionment, and health risk assessment of phthalate esters in indoor dust samples across China. Environmental Sciences Europe 33

30. Li Y, Zhan J, Zhang F, Zhang M, Chen D (2017) : The study on ecological sustainable development in Chengdu. Physics and Chemistry of the Earth, Parts A/B/C 101, 112-120

31. Lovekamp-Swan T, Davis BJ (2002) Mechanisms of Phthalate Ester Toxicity in the Female Reproductive System. Environ Health Perspect 111:139-145

32. Luo X, Shu S, Feng H, Zou H, Zhang Y (2021) Seasonal distribution and ecological risks of phthalic acid esters in surface water of Taihu Lake, China. Sci Total Environ 768:144517

33. Lv Y, Fang Y, Chen P, Duan Y, Huang T, Ma L, Xie L, Chen X, Chen X, Gao J, Ge RS (2019) Dicyclohexyl phthalate blocks Leydig cell regeneration in adult rat testis. Toxicology 411:60-70

34. Ma B, Wang L, Tao W, Liu M, Zhang P, Zhang S, Li X, Lu X (2020) Phthalate esters in atmospheric PM2.5 and PM10 in the semi-arid city of Xi'an, Northwest China: Pollution characteristics, sources, health risks, and relationships with meteorological factors. Chemosphere 242:125226

35. Man JY (2011) Affordable housing in China. Land Lines 1:16-20

36. Müller AK, Nielsen E, Ladefoged O, Dalgaard M, Hass U (2006) : Evaluation of the health risk to animals playing with phthalate containing toys. No.74

37. Net S, Sempere R, Delmont A, Paluselli A, Ouddane B (2015) Occurrence, fate, behavior and ecotoxicological state of phthalates in different environmental matrices. Environ Sci Technol 49:4019-4035

38. Orecchio S, Indelicato R, Barreca S (2013) The distribution of phthalate esters in indoor dust of Palermo (Italy). Environ Geochem Health 35:613-624

39. Pei J, Sun Y, Yin Y (2018) The effect of air change rate and temperature on phthalate concentration in house dust. Sci Total Environ 639:760-768

40. Salthammer T, Zhang Y, Mo J, Koch HM, Weschler CJ (2018) Assessing Human Exposure to Organic Pollutants in the Indoor Environment. Angew Chem Int Ed Engl 57:12228-12263

41. Schecter A, Lorber M, Guo Y, Wu Q, Yun SH, Kannan K, Hommel M, Imran N, Hynan LS, Cheng D, Colacino JA, Birnbaum LS (2013) Phthalate concentrations and dietary exposure from food purchased in New York State. Environ Health Perspect 121:473-494

42. Shi W, Chen J, Wang H (2016) Affordable housing policy in China: New developments and new challenges. Habitat International 54:224-233

43. Shinohara N, Mizukoshi A, Uchiyama M, Tanaka H (2019) Emission characteristics of diethylhexyl phthalate (DEHP) from building materials determined using a passive flux sampler and micro- 
chamber. PLoS ONE 14:e0222557

44. Skrbic BD, Ji Y, Durisic-Mladenovic N, Zhao J (2016) Occurence of the phthalate esters in soil and street dust samples from the Novi Sad city area, Serbia, and the influence on the children's and adults' exposure. J Hazard Mater 312:272-279

45. Song D, Sun H, Yang Y, Wang X, Sun Y, Liu X, Huang M, Feng C, Zhuang Y, Zhang J, Kong F (2020) Status of phthalate esters in tobacco cultivation soils and its health risk to Chinese people. J Soils Sediment 21:307-318

46. UNDESA (2018) World Urbanization Prospects: The 2018 Revision, Key Facts. United Nations Department of Economics and Social Affairs, Population Division, New York, NY, USA

47. USEPA (1996a) Method 3540C: Soxhlet extraction. Environmental Protection Agency; Washington, DC

48. USEPA (1996b) Method 3620B: Florisil Cleanup. Enrionmental Protection Agency, Wachington, DC

49. Wang L, Zou Y, Wu P, Meng J, Zhang R (2020) Phthalate exposure in pregnant women and the influence of exposure to environmental tobacco smoke. J Matern -Fetal Neonatal Med 33:31113115

50. Wang W, Wu FY, Huang MJ, Kang Y, Cheung KC, Wong MH (2013) Size fraction effect on phthalate esters accumulation, bioaccessibility and in vitro cytotoxicity of indoor/outdoor dust, and risk assessment of human exposure. J Hazard Mater 261:753-762

51. Wang X, Tao W, Xu Y, Feng J, Wang F (2014) Indoor phthalate concentration and exposure in residential and office buildings in Xi'an, China. Atmos Environ 87:146-152

52. WHO (2020) : World Health Organization. Coronavirus disease 2019 (COVID-19): situation report, 72

53. Wooten KJ, Smith PN (2013) Canine toys and training devices as sources of exposure to phthalates and bisphenol A: quantitation of chemicals in leachate and in vitro screening for endocrine activity. Chemosphere 93:2245-2253

54. Xia M, Ouyang X, Wang X, Shen X, Zhan Y (2018) Occupational exposure assessment of phthalate esters in indoor and outdoor microenvironments. J Environ Sci (China) 72:75-88

55. Xu H, Kou L, Wall G (2018) Retired Tibetan migrants' adaptation experiences in Chengdu, China. Asian Ethnicity 19:319-343

56. Yang Y, Zhang D, Meng Q, Yu W, Yuan L (2017) Stratified evolution of urban residential spatial structure in China through the transitional period: A case study of five categories of housings in Chengdu. Habitat Int 69:78-93

57. Zhang Q, Lu X-M, Zhang X-L, Sun Y-G, Zhu D-M, Wang B-L, Zhao R-Z, Zhang Z-D (2013) Levels of phthalate esters in settled house dust from urban dwellings with young children in Nanjing. China Atmos Environ 69:258-264

58. Zhang Q, Sun Y, Zhang Q, Hou J, Wang P, Kong X, Sundell J (2020) Phthalate exposure in Chinese homes and its association with household consumer products. Sci Total Environ 719:136965 
59. Zhu Q, Jia J, Zhang K, Zhang H, Liao C, Jiang G (2019) Phthalate esters in indoor dust from several regions, China and their implications for human exposure. Sci Total Environ 652:1187-1194

\section{Figures}

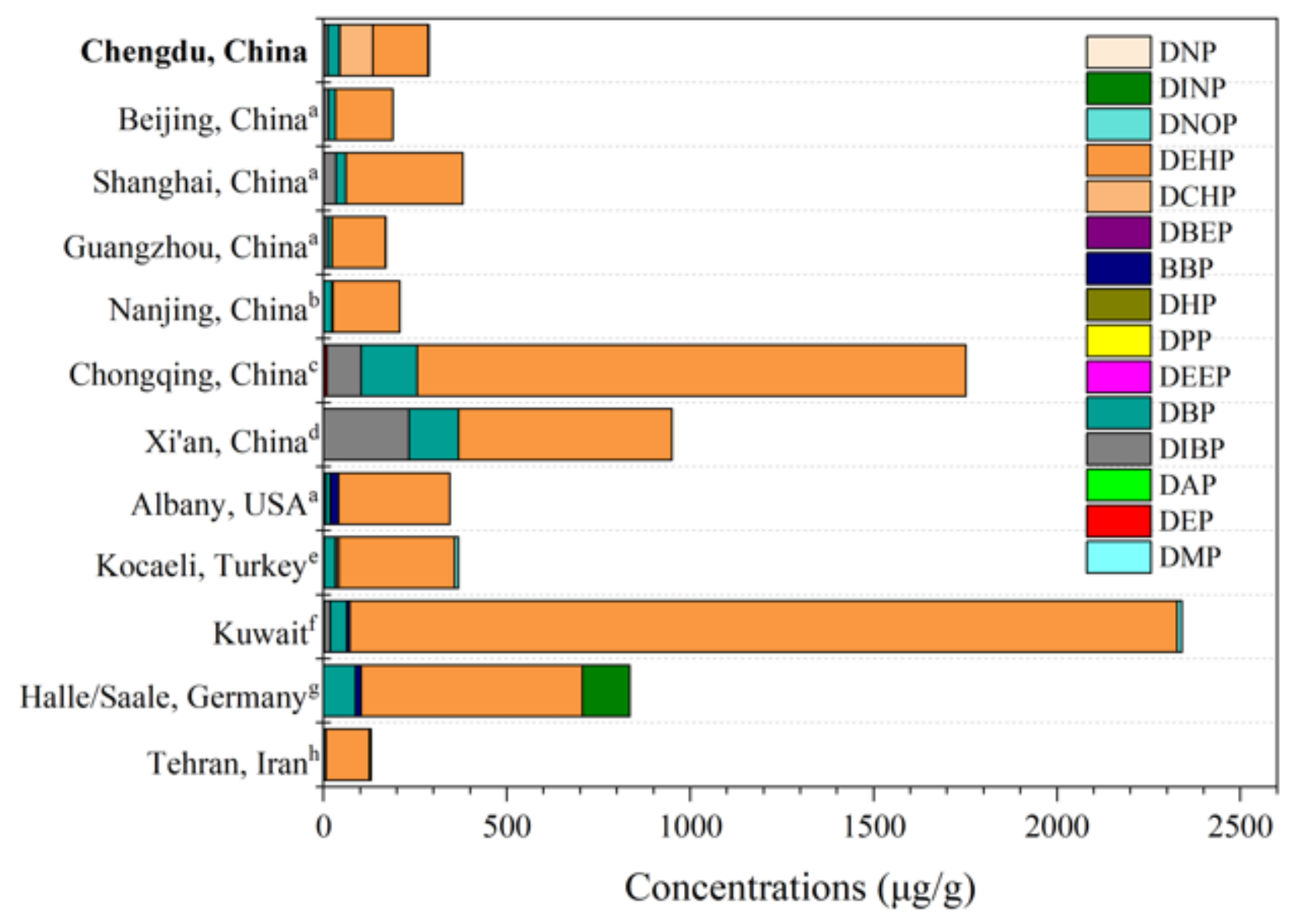

Figure 1

Concentrations $(\mu \mathrm{g} / \mathrm{g})$ of phthalate esters in household dusts in Chengdu and other cities around the world. 


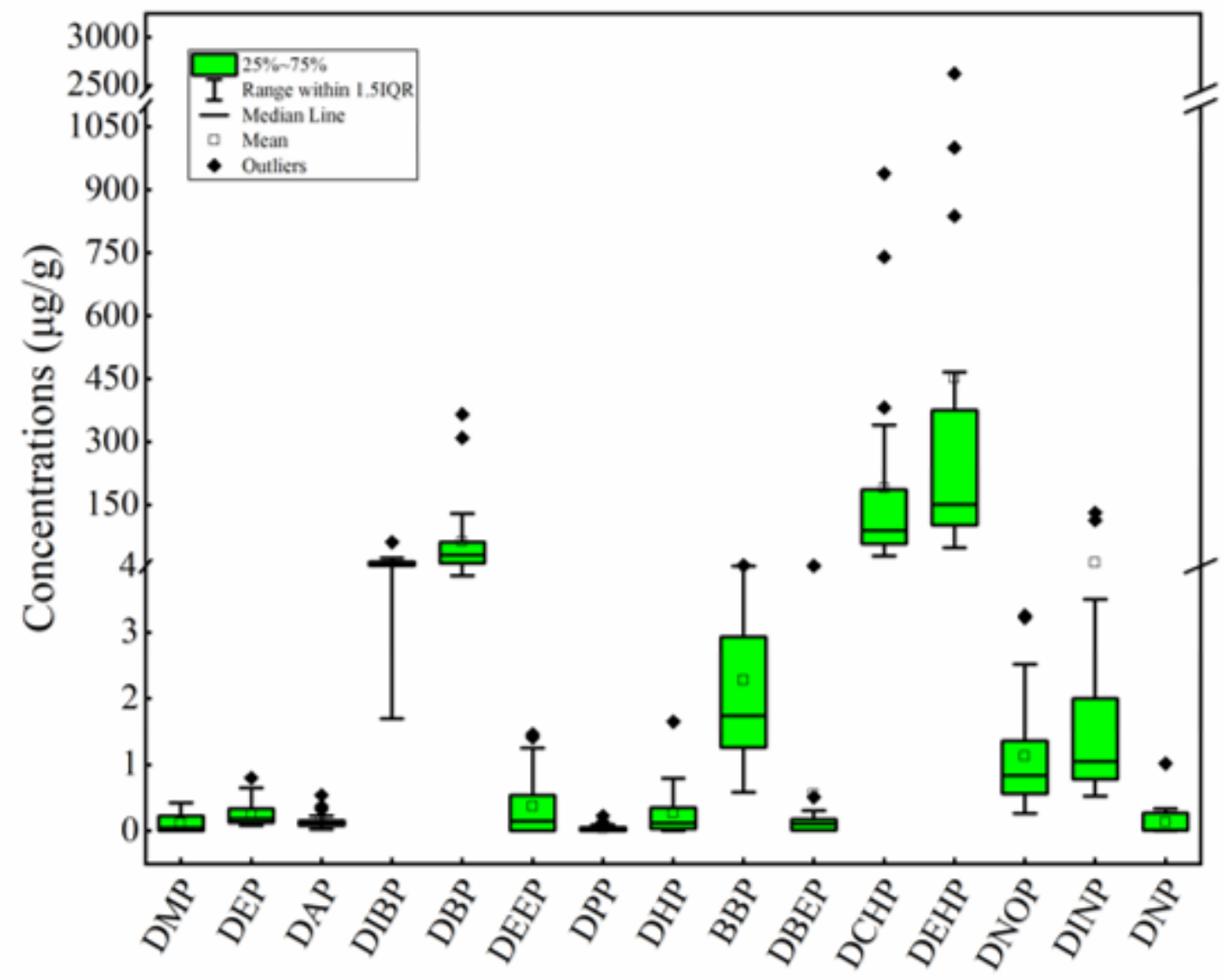

Figure 2

The concentration $(\mu \mathrm{g} / \mathrm{g})$ of individual phthalate esters in household dusts from Chengdu. 


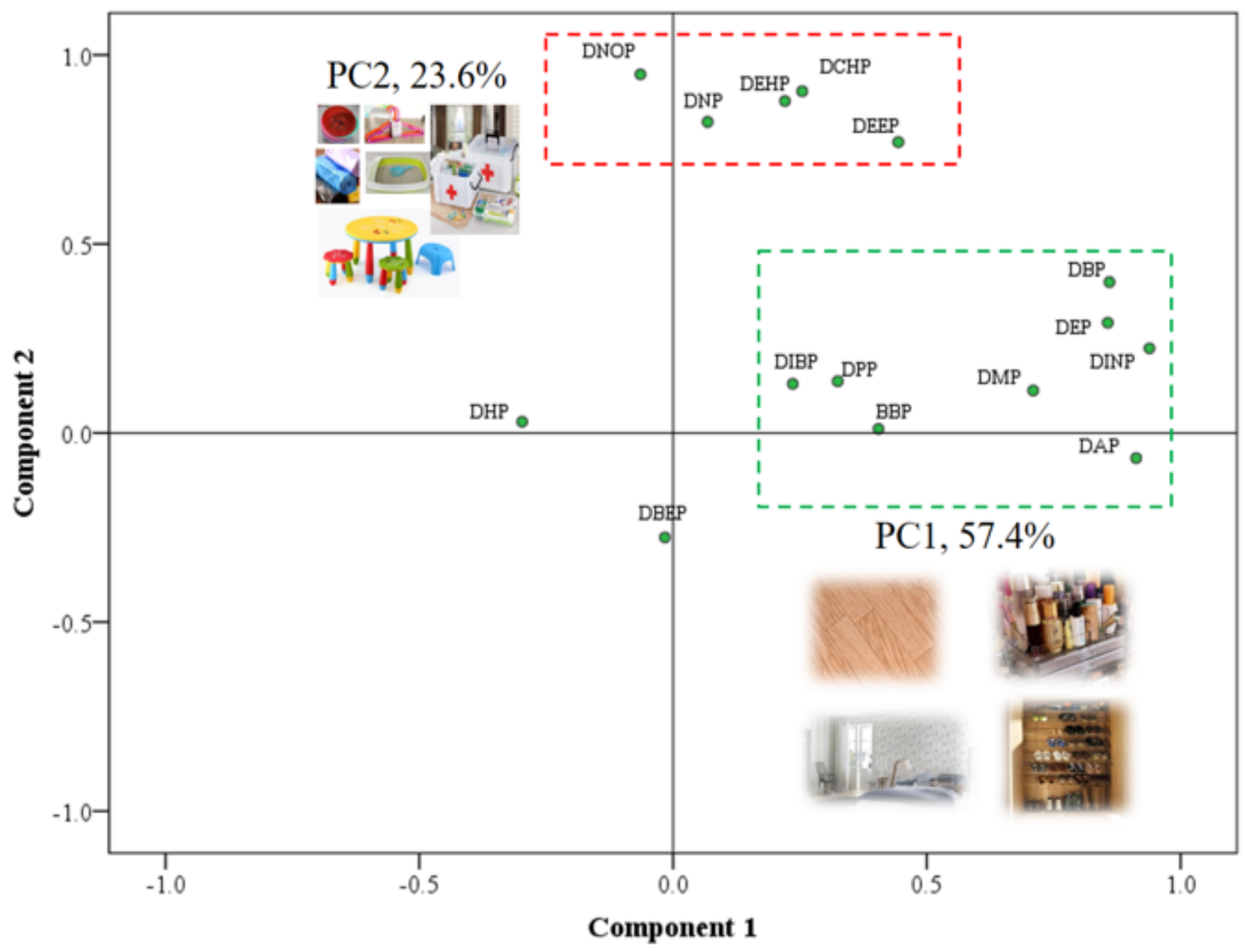

Figure 3

Principal component analysis of phthalate esters in the household dusts. 


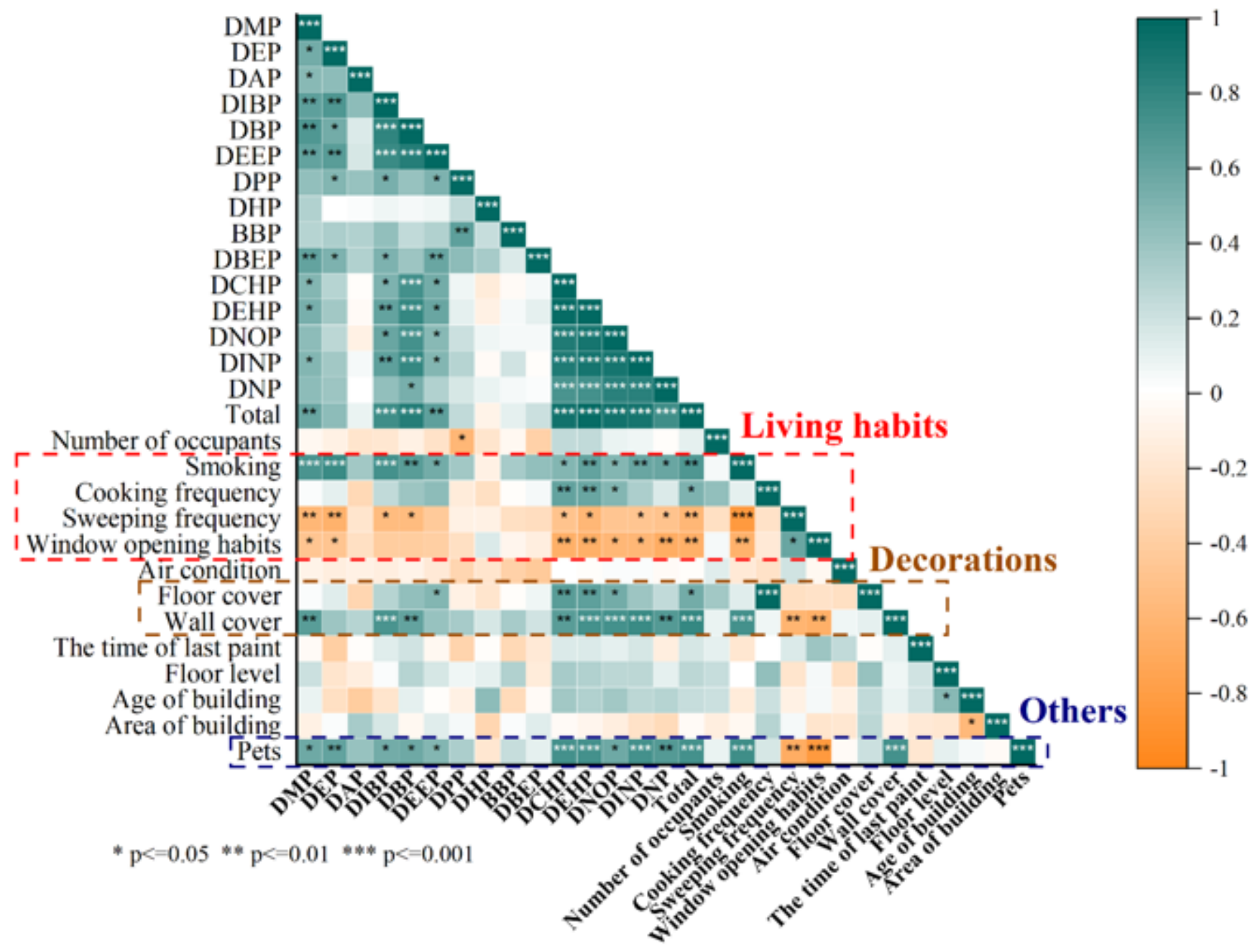

Figure 4

Relationships between the household factors and phthalate esters concentrations in the household dust .

\section{Supplementary Files}

This is a list of supplementary files associated with this preprint. Click to download.

- Supplementarymaterial.docx 